\title{
Examining the mechanisms by which women's status and empowerment affect skilled birth attendant use in Senegal: a structural equation modeling approach
}

\author{
Kyoko Shimamoto ${ }^{*}$ and Jessica D. Gipson
}

\begin{abstract}
Background: Despite the reduction in maternal deaths globally, maternal mortality rates remain unacceptably high, particularly in some regions of the world. In sub-Saharan Africa, maternal mortality rates have even increased recently, with 201,000 deaths in 2015 as compared to 179,000 in 2013. Use of a skilled birth attendant (SBA) at delivery has remained low, despite evidence of the effectiveness of SBAs in reducing maternal deaths. Women's empowerment is increasingly recognized as a key determinant of maternal health care-seeking and outcomes, yet empirical examinations of the linkages between women's empowerment and delivery care use are particularly limited, especially from sub-Saharan Africa.
\end{abstract}

Methods: Using data from the 2010 Senegal Demographic and Health Survey $(n=7451)$, in this study we employed structural equation modeling (SEM) to investigate the complex and multidimensional pathways by which three women's empowerment domains (household decision-making, attitudes towards violence, and sex negotiation) directly and indirectly affect SBA use.

Results: Although variations were observed across measures, many of the women's status and empowerment measures were positively related to SBA use. Notably, women's education demonstrated a substantial indirect effect: higher education was related to older age at first marriage, which was associated with higher levels of empowerment and SBA use. In addition to age at first marriage, gender-role attitudes (e.g., progressive attitudes towards violence and sex negotiation) were significant mediators in the relationship between education and SBA use. However, household decision-making was not significantly associated with SBA use.

Conclusions: Findings indicate significant effects of women's education, early marriage, and some dimensions of women's empowerment on SBA use. SEM was particularly useful in examining the complex and multidimensional constructs of women's empowerments and their effects. This study informs policy recommendations and programmatic efforts to reduce maternal mortality in sub-Saharan Africa by strengthening support for women's access to higher education, delaying marriage and childbearing among girls and young women, and supporting more equitable gender norms.

Keywords: Maternal mortality, Delivery care, Skilled birth attendant, Women's status, Women's empowerment, Structural equation modeling, Sub-Saharan Africa

\footnotetext{
* Correspondence: kyoko0517@ucla.edu

Fielding School of Public Health, University of California, Los Angeles, 650

Charles E. Young Dr. South, 16-035 Center for Health Sciences, Los Angeles,

CA 90095-1772, USA
} 


\section{Background}

Maternal mortality remains unacceptably high in lowand middle-income countries, where $99 \%$ of maternal deaths occur. In 2015, 303,000 women died from causes related to pregnancy and childbirth globally, most of which were preventable. Sub-Saharan Africa (SSA) has some of the highest rates of maternal mortality, with an average maternal mortality ratio (MMR) of 546 (per 100,000 live births), as compared to the global average of 216. The risk of maternal death has even increased most recently in SSA, and stark disparities remain in the lifetime risk of maternal death when comparing SSA (1 in 36$)$ to the global average (1 in 180) [1].

Delivery assistance by a skilled health professional is critical to reduce maternal and newborn deaths: it is the most effective and cost-effective approach [2-4]. The global World Health Organization (WHO) definition of a skilled birth attendant (SBA) is "an accredited health professional - such as a midwife, doctor, or nurse - who is proficient in the skills needed to manage normal (uncomplicated) pregnancies and childbirth, and to identify, manage and refer complications in women and newborns" [2]. Availability and quality of delivery care with an SBA is estimated to avert 16-33\% of maternal deaths [5].

Despite such evidence, levels of SBA use remain low, particularly in SSA where only half of deliveries have an SBA present [6]. In SSA and other low-resource settings, further reductions in maternal mortality are inhibited by a complex set of factors that affect women's access to and use of maternity health care services. For example, low socioeconomic status (low education and economic status), long distances to facilities, insufficient transportation, lack of qualified staff and supplies, and poor quality of care are negatively associated with delivery care use and health outcomes for mothers and newborns [7-10]. There is growing evidence that women's social status and the power they wield in their households, communities, and societies are key determinants of delivery care use and its associated health outcomes [7, 10-13], which are necessary to achieve social development, economic growth, and poverty reduction [14].

Women's status and empowerment are inherently complex constructs referred to in the empirical literature that serve to represent the social standing of women in society and their ability to participate in decision-making and to take action on issues affecting their own wellbeing and that of their families. Women's status is generally understood as "women's overall position in society" [15] and is often operationalized as women's education, economic status, or employment [16]. On the other hand, women's empowerment is defined as "women's ability to make strategic life choices" - comprising three interrelated dimensions such as resources, agency, and achievements [16]. The existing literature often uses proxy measures for "resources" and "agency," including women's participation in household decision-making, access to and control over household resources, and attitudes towards gender relationships $[11,16,17]$.

Despite the recognized importance of women's status and empowerment on health and social outcomes, the empirical literature examining the impacts of women's empowerment is insufficient in some substantive areas, and specific geographic regions are underrepresented in the literature. Although increasing, there are relatively few studies on the relationships between women's empowerment and delivery care use (i.e., presence of an SBA at delivery, institutional delivery) from African contexts despite increasing programmatic efforts and evidence indicating the influence of gender norm transformation on reproductive, maternal, and child health in SSA and elsewhere $[18,19]$. In the subset of SSA studies that examine women's empowerment as a multidimensional construct, we find unique and disparate effects of empowerment dimensions on delivery care use [4, 20-23]. For example, a multi-country study in eight African countries found varied influences of women's empowerment domains (i.e., household decision-making, financial decision-making, attitudes towards violence and sex negotiation) on the likelihood of women delivering at a health care facility [20,22]. In particular, women's household decision-making was positively associated with delivery at a health facility only in Nigeria, yet in the rest of the seven countries this showed no significant effect on facility-based delivery care.

Examination of the linkages between women's empowerment and SBA use is particularly important in Senegal, where continuous social and development efforts towards gender equality are resulting in gradual shifts in gender norms and relations [24-26]. Women's higher social status has been found to be a critical determinant of facility-based delivery care-seeking in Senegal $[27,28]$, suggesting that efforts to improve gender equality may also further promote SBA use.

The varied effects of women's empowerment on maternal health care-seeking may be due, at least in part, to two key methodological challenges in this area of study. First, there are inconsistent operationalizations and measurements of empowerment across studies and settings $[11,17]$. Despite the importance of capturing the multiple dimensions of empowerment [16], summative measures or composite indices are often used that likely mask the unique and potentially countervailing influences of each empowerment dimension, though there are some exceptions of studies that have incorporated multidimensional measures [4, 20-23, 29, 30].

Second, although structural equation modeling (SEM) has been used to examine mechanisms influencing pregnancy and child health in studies from higher income countries [31, 32], there are no known studies using 
SEM that empirically test the complex linkages between multidimensional measures of empowerment and delivery care use from low-income countries.

Given these identified gaps in the literature, this study employed SEM and aimed to examine the mechanism linking women's status, empowerment, and SBA use in Senegal, a setting where women's status and empowerment remain constrained and a substantive proportion of births are unattended by an SBA. In particular, this study first examined the relationship of women's education, age at first marriage, and multiple empowerment dimensions with SBA use. Second, the mediation effects of age at first marriage and empowerment dimensions were assessed as potential intervening constructs in the pathway between women's education and SBA use.

\section{Methods}

\section{Study setting and data}

Although maternal mortality has declined in Senegal over the last two decades (from 540 in 1990 to 315 in 2015) [1], rates still exceed those in other regions. Further reductions in maternal mortality likely hinge on increasing SBA use at delivery. More than one-third of women do not have a delivery attended by an SBA, and there are stark disparities in access to care by sociodemographic characteristics, including geographic residence (e.g., urban-rural) and household wealth [26].

This study used data from the 2010-2011 Senegal Demographics and Health Survey (DHS), a nationally representative household survey [26]. The study sample comprises currently married women who had at least one birth during the 5 years preceding the survey. Unmarried women were dropped from the analysis, because questions on household decision-making were asked of married women only. Also, women with missing data on the decision-making, gender attitudes, and sociodemographic variables were dropped, yielding a final analytic sample of 7451 . The proportion of missing observations is marginal - only 1.6 percent - thus, the potential bias due to missing data is negligible.

\section{Conceptual framework}

This analysis employed an integrated conceptual framework to examine the pathways linking women's status and empowerment to SBA use, based on the existing conceptual definitions and the Theory of Gender Stratification $[16,33]$. As shown in Fig. 1, women's status, operationalized as women's education, positively affects multiple dimensions of empowerment, which in turn promotes SBA use. According to the theory, women with greater power have more control over their lives and a variety of "life options" [33, 34]. Household decision-making power and attitudes towards gender norms represent "agency" and "resource" dimensions of empowerment, and they are frequently examined in studies using DHS data. This framework also considers the potential negative influence of early marriage on empowerment and delivery care use. The potential confounding effects of sociodemographic characteristics of women and households were controlled, as well as perceived difficulty in accessing health care.

\section{Analytic strategy and measures}

A latent variable SEM was employed for this study, which included both a structural portion (i.e., with measured variables) and a measurement portion (i.e., with latent constructs). The latent variable SEM comprised three latent constructs, each of which included individual empowerment indicators to represent each empowerment dimension. The

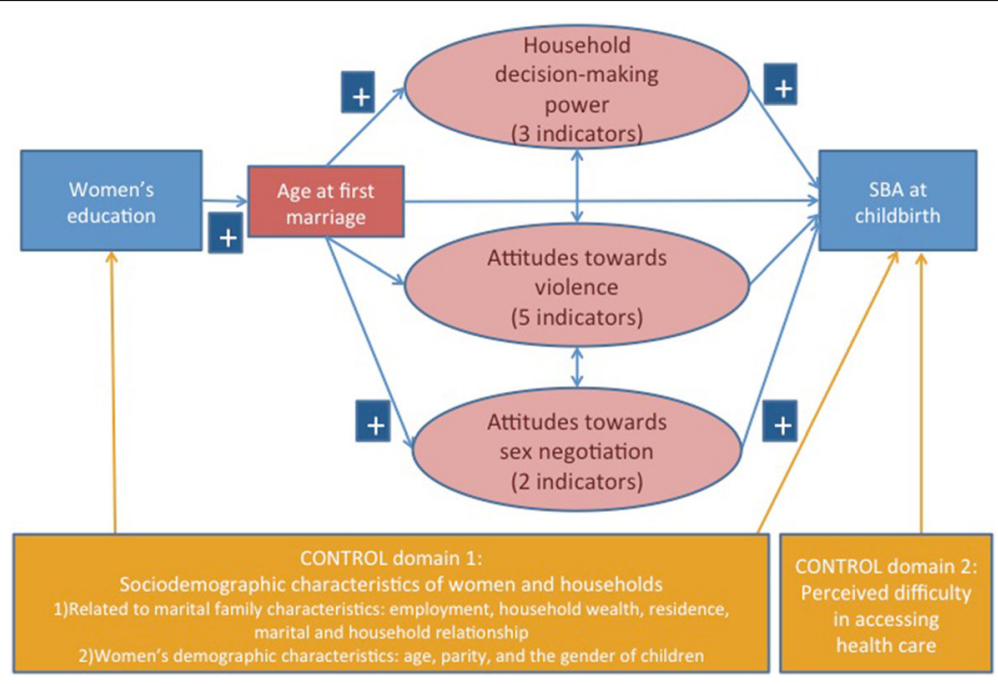

Fig. 1 A conceptual framework on women's status, empowerment, and SBA use 
latent variable SEM included five "endogenous variables" (those that appear as dependent variables in at least one equation in the SEM) and multiple "exogenous variables" (those that are never dependent variables in the SEM) [35]. Endogenous variables were SBA use, household decisionmaking, gender-role attitudes, and age at first marriage. Exogenous variables were women's education, sociodemographic characteristics of women and households, and perceived difficulty in accessing health care. Operationalizations of these measures were determined based on the existing theory and literature review and have been employed in a separate analysis by the authors [4].

\section{Endogenous variables}

SBA use at childbirth was operationalized as the use of $\mathrm{SBA}(\mathrm{s})$ at the last childbirth per the WHO definition [2]. SBAs included doctors or assistant medical officers, clinical officers, nurses, or midwifes; non-SBAs included village health workers, traditional birth attendants, relatives or friends, others, or no one at the delivery [36]. Based on these answer options in the survey, the variable was recoded into binary form.

Age at first marriage was examined as a continuous variable. In the survey, MEASURE DHS calculated the age at first marriage based on the date of the first marriage or union ("living with a man as if married") and the respondent's date of birth [36].

Household decision-making power was examined as a latent construct consisting of three indicators: women's participation in decisions regarding their own health care, major household purchases, and visits to family/ relatives [36]. These questions were asked only to women who were currently married/in union. The variables were first recoded to examine if women participated in decisions (i.e., alone/jointly with their husband) or not. A latent variable was constructed from the three binary variables for each decision.

Attitudes towards violence were examined as a latent construct consisting of five indicators concerning a woman's acceptance of wife-beating by her husband/ partner. The survey asked about the following five situations: if she goes out without telling him, neglects the children, refuses to have sex with him, argues with him, or burns the food [36]. Each variable was first recoded into binary data (i.e., yes accept, or no).

Attitudes towards sex negotiation were also assessed as a latent construct based on two questions. The questions assessed a woman's perceived ability to negotiate sexual relations, and the following two aspects were asked: if the respondent can refuse having sex or can ask her husband to use a condom $[4,36]$. Each variable was first recoded into binary form: the respondent can refuse/ask, or not (which included responses as cannot refuse/ask, don't know, not sure, or depends).

\section{Exogenous variables: women's education and control variables}

Women's education was measured as a continuous variable representing the number of years that the woman attended school. Sociodemographic characteristics of women and households were included in the model as control variables, as also employed in the separate analysis by the authors [4]: women's age, parity, employment for payment, household wealth, marital and household relationship, gender composition of children, place of residence, and a woman's education relative to her husband. Women's age and parity (i.e., the birth order of the child) were examined as continuous variables due to linear relationships with SBA use identified in descriptive analyses. Employment for payment was a binary measure that examined if a woman had been employed (for cash or in-kind), or not, in the last 12 months. Household wealth was determined based on reported ownership of household assets (e.g., consumer items and home attributes). A composite index was created by MEASURE DHS, based on the results of principal component analysis and divided into quintiles [36]. Marital relationship was included as the following: monogamous union, polygamous as a first wife, or polygamous as a second wife or lower, to consider differences by the type of relationship and wife order given evidence of differences in women's status and power across these relationship types [37-39]. Household relationship, a binary variable, was examined if the respondent was a household head or not. The gender composition of children examined if the respondent had at least one living son or not, because having a son has been shown to be an important reflection of African women's status and power [40]. The place of residence was a binary measure; it denoted if the respondent lived in an urban or rural area. Woman's education relative to husband's was assessed as continuous, whereas relative age was assessed but not included in the final model due to non-significant results.

Perceived difficulty in accessing health care was also included as a control variable, and the survey examined the following four aspects: getting permission to go; distance to the health care facility; getting money needed for advice/treatment; or not wanting to go alone [36]. The first item on permission was somewhat related to decision-making as a construct of empowerment, while the other three items measured broader socioeconomic factors particularly related to financial and geographic access to health facilities. Each variable was first recoded into a binary variable to demonstrate if the respondent perceived a big problem, or not (i.e., including the answer options of "not a big problem" and "not a problem at all"). A continuous variable showed the number of aspects for which the respondent perceived difficulties (scored 0-4). 


\section{Analytic models and steps}

Data analysis consisted of three steps. The first step was to undertake descriptive analyses using SAS 9.3. The second step was to conduct factor analyses using Mplus version 7.3 with a geomin rotation. Exploratory factor analysis (EFA) identified the number of factors/latent constructs and the underlying factor structure of empowerment, and then three-factor confirmatory factor analysis (CFA) examined the appropriateness and generalizability of the measurement portion of the SEM. The third step was to employ SEM with Mplus to examine the pathways from women's education to SBA use. All the analyses were conducted using polychoric correlations for categorical variables, and accounted for individual weights and a two-stage cluster sampling design to address disproportionate sampling and design effects of more than 1.00 [41].

The SEM separately regressed SBA use, household decision-making power, attitudes towards violence, attitudes towards sex negotiation, and age at first marriage using probit regression with weighted least squares means and variance adjusted (WLSMV). This SEM employed listwise deletion with missing observations. In the model, all of the exogenous variables were designated as covarying because of potential relatedness. Also, the errors/disturbances of empowerment dimensions were all covarying, as the unobserved aspects of these constructs were also likely to be interrelated.

Model fit was assessed using recommended model fit indices: root mean square error of approximation (RMSEA) $<0.06$ (or less as a "close" fit) and a comparative fit index (CFI)/Tucker-Lewis index (TLI) $\geq 0.95$ [42]. Weighted root mean square residual (WRMR) (less than 0.90) was also calculated by Mplus for the models with categorical endogenous variables [43].

\section{Results}

Descriptive results

Around two-thirds of the respondents used an SBA at the last birth (Table 1). Overall, women's reported levels of household decision-making were low, and gender norm attitudes were permissive. Women got married or started a union at mean age 18.3 years and had on average less than 2 years of formal education.

\section{Factor analysis results}

The EFA results indicated three factors (eigenvalues >1.0) [44]: (1) household decision-making power (three indicators), (2) attitudes towards violence (five indicators), and (3) attitudes towards sex negotiation (two indicators). See Table 2. The three factors were significantly, yet not highly, correlated with factor correlations less than 0.31 $(p<0.05)$, indicating the distinction of each factor.
Table 1 Characteristics of participating, currently married women with at least one birth in last 5 years $(n=7451)$, Senegal DHS 2010

\begin{tabular}{|c|c|c|c|}
\hline \multirow[t]{2}{*}{ Variables } & \multirow[t]{2}{*}{ Freq. } & Weighted & \multirow[t]{2}{*}{ SE } \\
\hline & & $\begin{array}{l}\text { Mean or } \\
\text { proportion }\end{array}$ & \\
\hline \multicolumn{4}{|l|}{ Outcome } \\
\hline $\begin{array}{l}\text { Skilled birth attendant use at the last } \\
\text { childbirth }\end{array}$ & 4251 & 66.30 & 1.27 \\
\hline \multicolumn{4}{|l|}{ Mediators: women's empowerment measures } \\
\hline $\begin{array}{l}\text { Household decision-making (mean, } \\
\text { scored 0-3) }\end{array}$ & & 0.92 & 0.03 \\
\hline Attitudes towards violence (mean, $0-5$ ) & & 2.80 & 0.05 \\
\hline $\begin{array}{l}\text { Attitudes towards sex negotiation } \\
\text { (mean, } 0-2 \text { ) }\end{array}$ & & 0.60 & 0.02 \\
\hline Age at first marriage (mean) & & 18.29 & 0.10 \\
\hline \multicolumn{4}{|l|}{$\begin{array}{l}\text { Demographics and perceived accessibility } \\
\text { of health care }\end{array}$} \\
\hline Education (mean in years) & & 1.79 & 0.08 \\
\hline Current age & & 29.40 & 0.12 \\
\hline \multicolumn{4}{|l|}{ Household wealth quintile } \\
\hline Poorest & 2264 & 22.38 & 1.31 \\
\hline Poorer & 1882 & 20.95 & 1.18 \\
\hline Middle & 1534 & 19.19 & 1.13 \\
\hline Richer & 1056 & 19.85 & 1.34 \\
\hline Richest & 715 & 17.63 & 1.12 \\
\hline \multicolumn{4}{|l|}{ Employment for payment } \\
\hline $\begin{array}{l}\text { Currently employed or employed } \\
\text { last } 12 \text { months }\end{array}$ & 3386 & 46.04 & 1.12 \\
\hline $\begin{array}{l}\text { Parity (total number of children } \\
\text { ever born) }\end{array}$ & & 3.81 & 0.04 \\
\hline \multicolumn{4}{|l|}{ Marital relationships } \\
\hline Monogamous union & 4909 & 68.19 & 0.83 \\
\hline Polygamous as 1 st wife & 991 & 12.73 & 0.44 \\
\hline Polygamous as 2nd or lower & 1550 & 19.08 & 0.55 \\
\hline Household head & 322 & 4.98 & 0.38 \\
\hline \multicolumn{4}{|l|}{ Place of residence } \\
\hline Urban & 2267 & 39.95 & 1.62 \\
\hline Rural & 5184 & 60.05 & 1.62 \\
\hline $\begin{array}{l}\text { Perceived difficulty in accessing } \\
\text { health care (Mean, scored 0-4) }\end{array}$ & & 1.23 & 0.04 \\
\hline
\end{tabular}

Frequency missing $=119$ (with attitudes towards violence), 1 (with marital relationships)

SE standard error

\section{SEM results}

The final adjusted SEM results are presented in Table 3 and Fig. 2. The standardized path coefficients and $p$ values in the unstandardized metric are reported. The model fit statistics (RMSEA, CFI/TLI, WRMR) show that the models fit the data well. 
Table 2 Factor analysis for indicators of empowerment $(n=7451)$, Senegal DHS 2010-2011

\begin{tabular}{llcl}
\hline Latent construct & Aspects asked about by survey & Factor loadings (EFA) & $t$ value (CFA) \\
\hline Household decision-making & Decision on own health care & 0.916 & 0.869 \\
& Decision on major household purchases & 0.851 & 38.927 \\
& Decision on visits to family or relatives & 0.917 & 0.933 \\
Attitudes towards violence & Violence if she goes out without telling her husband & 0.963 & 101.880 \\
& Violence if she neglects the children & 0.911 & 122.107 \\
& Violence if she argues with him & 0.822 & 0.803 .322 \\
Giolence if she refuses to have sex with him & 03.985 & - \\
& Violence if she burns the food & 0.771 & 8.305 \\
\hline
\end{tabular}

In the CFA, the path of the first indicator is constrained to 1 (thus $t$ value was not calculated). Significance of $t$ values refers to unstandardized parameter values. All the factor loadings are significant at $p<0.05$. RMSEA $=0.016, \mathrm{CFI}=0.998, \mathrm{TLI}=0.997$, WRMR $=1.012$

Table 3 Standardized path coefficients of the latent variable SEM $(n=7451)$, Senegal DHS 2010-2011

\begin{tabular}{|c|c|c|c|c|c|}
\hline \multirow[t]{2}{*}{ Predictors in the equation $(X)$ : } & \multicolumn{5}{|c|}{ Dependent variables in the equation $(Y)$ : } \\
\hline & $\begin{array}{l}\text { [Column 1] } \\
\text { Age at first } \\
\text { marriage }\end{array}$ & $\begin{array}{l}\text { [Column 2] } \\
\text { Decision-making } \\
\text { power }\end{array}$ & $\begin{array}{l}\text { [Column 3] } \\
\text { Attitudes towards } \\
\text { violence }\end{array}$ & $\begin{array}{l}\text { [Column 4] } \\
\text { Attitudes towards } \\
\text { sex negotiation }\end{array}$ & $\begin{array}{l}\text { [Column 5] } \\
\text { SBA use }\end{array}$ \\
\hline \multicolumn{6}{|l|}{ Endogenous variables } \\
\hline (1) Age at first marriage & & -0.014 & 0.003 & $0.046^{*}$ & 0.020 \\
\hline (2) Decision-making power & & & & & 0.005 \\
\hline (3) Attitudes against violence & & & & & $0.062^{*}$ \\
\hline (4) Attitudes towards sex negotiation & & & & & $0.094^{* * *}$ \\
\hline \multicolumn{6}{|l|}{ Exogenous variables } \\
\hline Education & $0.102^{* * *}$ & $0.100^{* *}$ & $0.215^{* *}$ & $0.156^{* * *}$ & $0.068^{*}$ \\
\hline Age & $0.877^{* * *}$ & $0.097^{*}$ & 0.006 & 0.026 & $0.103^{* *}$ \\
\hline Parity & $-0.749^{* * *}$ & 0.042 & -0.031 & -0.020 & $-0.122^{* * *}$ \\
\hline Employment for payment & -0.022 & $0.160^{* * *}$ & 0.028 & -0.016 & $-0.039^{*}$ \\
\hline Household head & $-0.025^{*}$ & $0.070^{* * *}$ & -0.018 & 0.011 & 0.005 \\
\hline Urban residence & 0.008 & $0.101^{*}$ & $0.092^{*}$ & $0.093^{* *}$ & $0.170^{* * *}$ \\
\hline Having son(s) & -0.020 & -0.002 & -0.022 & 0.010 & $-0.047^{* *}$ \\
\hline Household wealth (the 2nd lowest) & $0.026^{*}$ & $-0.063^{*}$ & 0.001 & $0.086^{* * *}$ & $0.150^{* * *}$ \\
\hline Household wealth (the 3rd lowest) & $0.047^{* * *}$ & -0.034 & -0.021 & $0.117^{* * *}$ & $0.261^{* * *}$ \\
\hline Household wealth (the 4th lowest) & $0.066^{* * *}$ & -0.013 & -0.005 & $0.233^{* * *}$ & $0.342^{* * *}$ \\
\hline Household wealth (the highest) & $0.047^{*}$ & 0.040 & 0.074 & $0.260^{* * *}$ & $0.407^{* * *}$ \\
\hline Polygamous union as a first wife & $-0.090^{* * *}$ & -0.012 & 0.005 & -0.024 & $-0.039^{*}$ \\
\hline Polygamous union as a second or lower & $-0.027^{*}$ & -0.021 & -0.034 & $-0.070^{* * *}$ & $-0.045^{* *}$ \\
\hline Less education than husband & $0.042^{*}$ & 0.018 & $0.103^{* * *}$ & $0.048^{* *}$ & -0.004 \\
\hline More education than husband & -0.014 & -0.009 & -0.018 & -0.008 & $-0.070^{* *}$ \\
\hline Perceived difficulty in accessing health care & & & & & $-0.067^{* * *}$ \\
\hline
\end{tabular}

${ }^{* * *} p<0.001,{ }^{* *} p<0.01,{ }^{*} p<0.05$. Reference groups: residence $=$ rural; household wealth $=$ the lowest; marital relationship $=$ monogamous union; relative education $=$ almost the same education as husband

DF (Degree of Freedom) $=109, \mathrm{RMSEA}=0.011, \mathrm{CFI}=0.994, \mathrm{TLI}=0.991, \mathrm{WRMR}=0.915$

$R$ squared: 0.495 (age at first marriage), 0.113 (decision-making), 0.212 (attitudes towards violence), 0.130 (attitudes towards sex negotiation), 0.457 (SBA use) 


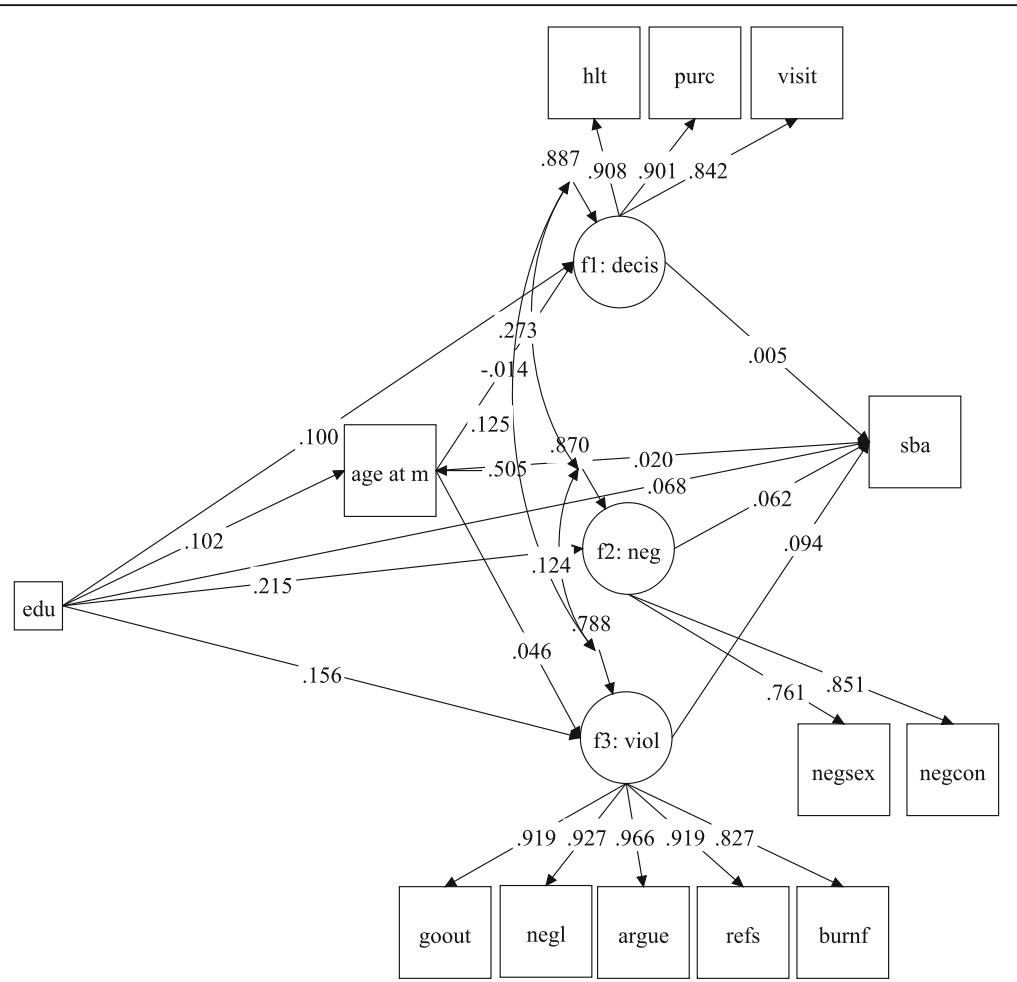

Fig. 2 A diagram of the latent variable SEM. sba SBA use, f1:decis decision-making power, f2:neg attitudes towards sex negotiation, f3:viol attitudes towards violence, age at $m$ age at first marriage, edu education. Standardized path coefficients are reported with the following significance levels: ${ }^{* * *} p<0.001,{ }^{* *} p<0.01,{ }^{*} p<0.05$. Factor loadings and correlations among disturbances are all significant at $p<0.001$. Control variables are not included in the figure

Women's education and gender-role attitudes were positively related to SBA use (Column 5 in Table 3). However, neither age at first marriage nor decisionmaking were directly related to SBA use. In addition, several sociodemographic variables were significantly related to SBA use, including women's age, urban residence, and higher household wealth. On the other hand, parity, paid employment, having living son(s), being in a polygamous union, husbands' lower education relative to women's, and perceiving difficulties in accessing health care were negatively related to SBA use.

Also, education and several other variables were positively related to older age at first marriage (Column 1 in Table 3). Significant and positive covariates in predicting age at first marriage included women's older age, higher wealth, and husband's higher education relative to women, whereas negative covariates were parity, heading household, and being in a polygamous union. Further, education was positively associated with all three empowerment dimensions: decision-making, attitudes towards violence, and attitudes towards sex negotiation (Columns 2-4, Table 3).

Moreover, apart from education, other sociodemographic variables were significantly, yet differently, related to the empowerment dimensions. Significant covariates in predicting decision-making included older age, paid employment and urban residence. Progressive attitudes towards violence were related to older age at first marriage, urban residence, higher wealth, and husband's higher education relative to wife, whereas polygamous marital relationship as second or lower wife order was associated with permissive attitudes. Concerning attitudes towards sex negotiation, urban residence and husband's higher education were also significantly and positively associated (Columns 2-4). Besides the significant correlations among the three empowerment dimensions per the factor analysis result, the SEM analysis showed that the residuals of these three factors were also significantly correlated with each other.

The direct and indirect effects of women's education on SBA use from the latent variable SEM are presented in Table 4. In addition to its direct effect, the total indirect effects of education on SBA use through all the identified pathways were significant. In particular, age at first marriage and attitudes towards violence and sex negotiation significantly mediated the relationship between education and SBA use. For example, women's higher education was related to older age at first marriage, which in turn positively influenced progressive attitudes towards violence and SBA use. The proportion of the 
Table 4 Summary of standardized direct and indirect effects of education on SBA use $(n=7451)$, Senegal DHS 2010-2011

\begin{tabular}{llcl}
\hline & & Coefficient & $t$ value \\
\hline Total effect & & 0.099 & $2.989^{* * *}$ \\
Direct effect & & 0.068 & $2.006^{*}$ \\
Total indirect effect & Age at first marriage & 0.031 & 0.002 \\
Indirect effect via: & Decision-making power & 0.000 & 0.015 \\
& Attitudes towards violence & 0.003 & 0.166 \\
& Attitudes towards sex negotiation & 0.013 & $3.217^{* * *}$ \\
& Age at first marriage then decision-making power & 0.000 & -0.161 \\
& Age at first marriage then attitudes towards violence & 0.000 & 0.000 \\
& Age at first marriage then attitudes towards sex negotiation & $1.975^{*}$ \\
\hline
\end{tabular}

${ }^{* * *} p<0.001,{ }^{* *} p<0.01,{ }^{*} p<0.05$

indirect effect of education over the total effect was substantial (31.3\%).

\section{Discussion}

This study examined the pathways linking women's status and empowerment to SBA use. The analysis provided evidence of the direct and indirect effects of education on SBA use through multiple empowerment dimensions, demonstrating evidence of potential causal mechanisms affecting SBA use. SEM is uniquely equipped to examine such complex mechanisms, by identifying and measuring intervening effects which are rarely empirically tested.

Four key findings arise from this analysis. First, the study showed the significant and positive effect of women's education on SBA use, with a significant proportion of indirect effects of education operating through the empowerment dimensions. This finding is generally consistent with previous evidence that women's education, as well as other sociodemographic characteristics, affect delivery care use and outcomes [4, 8, 20-23, 30, 45-50]. Evidence from this study suggests the influence of education as a key, direct driver for increasing delivery care use from skilled providers, possibly by advancing knowledge generally on the importance of seeking care for delivery care services as a means of mitigating risks of potentially life-threatening complications for mother and baby. Further, the indirect effects of education on delivery care use through age at first marriage and gender-role attitudes (towards violence and sex negotiation) underscore the importance of policy and program interventions to promote women's education for improving women's health, through women's empowerment and gender equity [6, 51-53].

Second, the significant influence of age at first marriage on delivery care use - directly and indirectly - is in alignment with increasing evidence of the critical influence of early marriage and childbearing on empowerment, delivery care use, and other reproductive health behaviors and outcomes [51, 54]. This study highlights the important linkages such that older age at first marriage is related to progressive gender-role attitudes, leading to higher likelihood of SBA use and likely better delivery outcomes.

Third, the evidence from this study highlights the critical role of gender-role attitudes in promoting delivery care-seeking in Senegal, and possibly other settings, where permissive gender norms persist. This finding is consistent with successes from sexual and reproductive health programs (e.g., HIV/AIDS prevention) which focused on transforming gender norms and integrating men as supportive partners $[19,55,56]$, as well as recent evidence from SSA finding positive influences of progressive gender-role attitudes on delivery care use [4, 20-22].

Fourth, the use of SEM in this analysis provided the simultaneous comparison of several empowerment dimensions on SBA use, clearly outlining variations in the magnitude and significance of each domain. The variations in the effects of independent empowerment domains on SBA use affirm the importance of operationalizing and measuring women's status and empowerment as a multidimensional construct, and the utility in identifying specific constructs or areas for subsequent intervention and policy efforts. For example, findings from this study suggest a prioritization of programs focusing on gender norm transformation and gender equality in Senegal, especially to promote equitable sexual negotiations between couples.

The null effects of household decision-making on SBA use, however, were unexpected yet consistent with previous studies showing an inconsistent influence of decisionmaking on delivery care use [4, 20-22]. Our analysis using hierarchical multivariate regression also showed no effect of decision-making on SBA use in a model excluding the two attitudinal measures of empowerment, while there was a significant bivariate relationship [4]. As noted by other scholars, the decisions on health care-seeking, 
particularly in a resource-constrained setting, are complex and contingent upon multiple logistical and structural factors $[7,10,13]$. Thus, the null findings from this analysis may be due to the limitation of existing measures in the survey. Indeed significant correlations among the residuals for these three empowerment dimensions suggest that there may be similar or shared features in the unexplained aspects of these factors. Further empirical and programmatic investigations are essential given increasing recognition of the role of women's status and empowerment as a means of achieving health and broader development goals $[13,14,52,53]$.

This study entails some limitations. First, despite the rigor of SEM, any causal inference is tentative, and potential reciprocal effects may exist, especially given the cross-sectional nature of the DHS survey data. However, relevant theories and descriptive results support the hypothesized causal relationships. Second, the operationalization and measurement of women's status and empowerment was limited by the available measures from the DHS, of which the relevance has been generally supported in Asia but less so in Africa [57]. Multi-dimensionality of empowerment has been underscored by the conceptual definition by Kabeer (2001) (e.g., "agency", "resources", "achievement") [16, 33], which could have been better captured in the survey. Third, the representativeness of the study sample and generalizability of the results are limited due to the omission of currently unmarried women. These women contributed $7.1 \%$ of all births that occurred $(n=576)$ in the study, yet since unmarried women were excluded from the decision-making questions, they were excluded from the analytic sample. Perhaps even more important to address in future program and research efforts is the omission of adolescents aged 10-14. Young adolescents are not interviewed in the DHS and other global surveys, despite the fact that a proportion of young adolescents will enter into marital relationships and begin childbearing at these ages in Senegal and several other African contexts. The underrepresentation of adolescents is critical, especially in light of growing evidence that adolescents are at greater risk of delivery without skilled professionals, unsafe abortion, and maternal deaths [51, 58-61].

\section{Conclusions}

Despite these weaknesses, this study is one of the first to use nationally representative data to examine complex pathways between women's empowerment and SBA use using SEM. The findings confirm the multidimensionality of empowerment and the need to examine critical intervening factors leading to reproductive and maternal health service use and outcomes. Moreover, this study highlights the need for policy and program interventions to support women's access to higher education, to delay marriage and childbearing among girls and young women, and to transform gender norms as a means of increasing SBA use and accelerating reductions in maternal mortality in Africa.

\section{Additional file}

Additional file 1: Open peer review. (PDF $155 \mathrm{~kb}$ )

\section{Abbreviations}

DHS: Demographic and Health Survey(s); SBA: Skilled birth attendant; SSA: Sub-Saharan Africa

\section{Acknowledgements}

The authors acknowledge the input and helpful suggestions of Peter $\mathrm{M}$. Bentler, Anne R. Pebley, Linda B. Bourque, and Patrick Heuveline; the UCLA Institute for Digital Research and Education; and the Macro International that conducted the Senegal Demographic and Health Surveys.

\section{Funding}

This article is part of a special issue on women's health and empowerment, led and sponsored by the University of California Global Health Institute, Center of Expertise on Women's Health, Gender, and Empowerment.

Shimamoto acknowledges financial support from the Joint Japan/World Bank Graduate Scholarship Program, the UCLA graduate division fellowship, and the UCLA Bixby doctoral fellowship. Gipson acknowledges financial support from the National Institute of Child Health and Human

Development (NICHD) Grant no. K01HD06767704. The authors benefited from facilities and resources provided by the California Center for Population Research at UCLA (CCPR), which receives core support (R24-HD041022) from the Eunice Kennedy Shriver NICHD.

\section{Availability of data and materials}

Data are publicly available at the MEASURE DHS program website. The permission to use the data was obtained after submission of the online request form through the website at https://dhsprogram.com.

\section{About this Supplement}

This article has been published as part of BMC Pregnancy and Childbirth Volume 17 Supplement 2, 2017: Special issue on women's health, gender and empowerment. The full contents of the supplement are available online at https://bmcpregnancychildbirth.biomedcentral.com/articles/supplements/ volume-17-supplement-2.

\section{Open peer review}

Peer review reports for this article are available in Additional file 1.

\section{Authors' contributions}

KS designed the study, conducted the analysis, and developed the manuscript. JG advised on the design of the study and assisted in drafting and revising the manuscript. Both authors read and approved the final manuscript.

\section{Authors' information}

KS was affiliated to the Department of Community Health Sciences, the Fielding School of Public Health, University of California, Los Angeles, USA. $J G$ is affiliated with the aforementioned Department.

\section{Ethics approval and consent to participant}

This study is a secondary data analysis of DHS data. The DHSs secured ethical clearance. The participant's informed consent was obtained by reading out the standard statement (i.e., verbal consent) by the interviewer during data collection, while a written consent was obtained prior to biomarker tests. 


\section{Consent for publication}

Not applicable.

\section{Competing interests}

The authors declare that they have no competing interests.

\section{Publisher's Note}

Springer Nature remains neutral with regard to jurisdictional claims in published maps and institutional affiliations.

\section{Published: 8 November 2017}

\section{References}

1. WHO. Trends in maternal mortality: 1990 to 2015. Estimates by WHO, UNICEF, UNFPA, The World Bank and the United Nations Population Division. Geneva: WHO Press; 2015.

2. WHO. Making pregnancy safer: the critical role of the skilled birth attendant a joint statement of WHO, ICM, and FIGO. Geneva: WHO Press; 2004

3. World Health Organization. Every newborn: an action plan to end preventable deaths. Geneva: World Health Organization; 2014

4. Shimamoto K, Gipson JD. The relationship of women's status and empowerment with skilled birth attendant use in Senegal and Tanzania. BMC Pregnancy Childbirth. 2015;15(1):154

5. Graham WJ, Bell JS, Bullough $\mathrm{CH}$. Can skilled attendance at delivery reduce maternal mortality in developing countries. Safe Motherhood Strateg. 2001:17:97-130.

6. Nations U. The Milennium Development Goals Report 2015. New York: United Nations; 2015.

7. Koblinsky M, Matthews Z, Hussein J, Mavalankar D, Mridha MK, Anwar I, Achadi E, Adjei S, Padmanabhan P, van Lerberghe W, et al. Materna Survival 3 - going to scale with professional skilled care. Lancet. 2006; 368(9544):1377-86.

8. Shiffman J. Can poor countries surmount high maternal mortality? Stud Fam Plan. 2000;31(4):274-89.

9. Ronsmans C, Graham WJ. Lancet Maternal Survival Series steering group. Maternal survival 1 - Maternal mortality: who, when, where, and why. Lancet. 2006:368(9542):1189-200.

10. Thaddeus S, Maine D. Too far to walk: maternal mortality in context. Soc Sci Med. 1994;38(8):1091-110.

11. Malhotra A, Shuler SR, Boender C. Measuring women's empowerment as a variable in international development. In: World Bank workshop on poverty and gender: New perspectives. Washington, DC: The World Bank; 2002.

12. Tunçalp Ö, Souza J, Hindin M, Santos C, Oliveira T, Vogel J, Togoobaatar G, Ha D, Say L, Gülmezoglu A. Education and severe maternal outcomes in developing countries: a multicountry cross-sectional survey. BJOG Int J Obstet Gynaecol. 2014;121(s1):57-65.

13. World Health Organization. Strategies towards ending preventable maternal mortality (EPMM). Geneva: World Health Organization; 2015.

14. World Bank. World Development Report 2012: gender equality and development. Washington, DC: World Bank Publications; 2012.

15. Safilios-Rothschild C. Female power autonomy and demographic change in the Third World. In: Anker R, Buvinic M, Youssef NH, editors. Women's roles and population trends in the Third World. London: Routledge; 1982

16. Kabeer N, McFadden P, Arnfred S, Dominguez E, Saaadallah S. Discussing women's empowerment: theory and practice. Sida studies no.3. Stockholm: Sida; 2001

17. Upadhyay UD, Gipson JD, Withers M, Lewis S, Ciaraldi EJ, Fraser A, Huchko MJ, Prata N. Women's empowerment and fertility: a review of the literature. Soc Sci Med. 2014;115:111-20.

18. Muralidharan A, Fehringer J, Pappa S, Rottach E, Das M, Mandal M. Transforming gender norms roles and power dynamics for better health: evidence from a systematic review of gender-integrated health programs in low- and middle-income countries. Washington, DC: Futures Group; 2015.

19. Interagency Gender Working Group. A summary report of new evidence that gender perspectives improve reproductive health outcomes. Washington, DC: Population Reference Bureau; 2011.

20. Singh K, Bloom S, Brodish P. Influence of gender measures on maternal and child health in Africa. MEASURE Evaluation Technical Report 66. Chapel Hill: MEASURE Evaluation; 2011

21. Singh K, Bloom S, Haney E, Olorunsaiye C, Brodish P. Gender factors and facility delivery: Nigeria and MDG5. Afr J Reprod Health. 2012;16:122-8.
22. Singh K, Bloom S, Brodish P. Gender equality as a means to improve maternal and child health in Africa. Health Care Women Int. 2015:36(1):57-69.

23. Woldemicael G, Tenkorang EY. Women's autonomy and maternal healthseeking behavior in Ethiopia. Matern Child Health J. 2010;14(6):988-98.

24. Patterson A. The impact of Senegal's decentralization on women in local governance. Can J Afri Stud/La Revue Canadienne des Etudes Africaines. 2002;36(3):490-529.

25. Agence Nationale de la Statistique et de la Demographie (ANSD) Senegal et ICF International. Enquete Demographique et de Sante a Indicateurs Multiples au Senegal (EDS-MICS) [DHS Senegal] 2005. Rockville: ANSD et ICF International; 2006.

26. Agence Nationale de la Statistique et de la Demographie (ANSD) Senegal et ICF International. Enquete Demographique et de Sante a Indicateurs Multiples au Senegal (EDS-MICS) [DHS Senegal] 2010-2011. Rockville: ANSD et ICF International; 2012.

27. Faye SL. Devenir mère au Sénégal: des expériences de maternité entre inégalités sociales et défaillances des services de santé. Cahiers d'études et de recherches francophones/Santé. 2008;18(3):175-83.

28. Faye A, Faye M, Bâ I, Ndiaye P, Tal-Dia A. Facteurs déterminant le lieu d'accouchement chez des femmes ayant bénéficié au moins d'une consultation prénatale dans une structure sanitaire (Sénégal). Rev Epidemiol Sante Publique. 2010;58(5):323-9.

29. Upadhyay UD, Karasek D. Womens empowerment and achievement of desired fertility in sub-Saharan Africa. DHS working papers. No. 80. US Aid: Calverton; 2010.

30. Austin A, Fapohunda B, Langer A, Orobaton N. Trends in delivery with no one present in Nigeria between 2003 and 2013. Int J Womens Health. 2015:7:345.

31. Walsh J, Hepper EG, Marshall BJ. Investigating attachment, caregiving, and mental health: a model of maternal-fetal relationships. BMC Pregnancy Childbirth. 2014;14(1):1

32. Ruiz RJ, Dwivedi AK, Mallawaarachichi I, Balcazar HG, Stowe RP, Ayers KS, Pickler R. Psychological, cultural and neuroendocrine profiles of risk for preterm birth. BMC Pregnancy Childbirth. 2015:15(1):1.

33. Blumberg RL. A general theory of gender stratification. Sociol Theory. 1984; 2:23-101.

34. Collins R, Chafetz JS, Blumberg RL, Coltrane S, Turner JH. Toward an integrated theory of gender stratification. Sociol Perspect. 1993;36(3):185-216.

35. Kline RB. Principles and practice of structural equation modeling. New York: Guilford Press; 2011

36. National Bureau of Statistics (NBS) Tanzania and ICF Macro. Tanzania Demographic and Health Survey 2010. Dar es Salaam: NBS and ICF Macro; 2011.

37. McCloskey LA, Williams C, Larsen U. Gender inequality and intimate partner violence among women in Moshi, Tanzania. Int Fam Plan Perspect. 2005; 31(3):124-30.

38. Larsen U, Hollos M. Women's empowerment and fertility decline among the Pare of Kilimanjaro region, Northern Tanzania. Soc Sci Med. 2003:57(6):1099-115.

39. Boye A-eK, Hill K, Isaacs S, Gordis D. Marriage law and practice in the Sahel. Stud Fam Plan. 1991:22(6):343-9.

40. Fuse K. Cross-national variation in attitudinal measures of gender preference for children: an examination of demographic and health surveys from 40 countries. DHS Working Papers No. 44. Calverton: US Aid; 2008.

41. ICF International. Demographic and health survey sampling and household listing manual. In: Measure DHS. Calverton: ICF International; 2012.

42. Hu L-t, Bentler PM. Cutoff criteria for fit indexes in covariance structure analysis: conventional criteria versus new alternatives. Struct Equ Model Multidiscip J. 1999;6(1):1-55.

43. Yu CY, Muthen B. Evaluation of model fit indices for latent variable models with categorical and continuous outcomes. In: Annual meeting of the American Educational Research Association, New Orleans, LA. 2002.

44. Pett MA, Lackey NR, Sullivan JJ: Making sense of factor analysis: The use of factor analysis for instrument development in health care research: Sage; 2003.

45. Ahmed S, Creanga AA, Gillespie DG, Tsui AO. Economic status, education and empowerment: implications for maternal health service utilization in developing countries. Plos One. 2010;5(6):e1190.

46. Woldemicael G. Do women with higher autonomy seek more maternal health care? Evidence from Eritrea and Ethiopia. Health Care Women Int 2010:31(7):599-620.

47. Jayaraman A, Chandrasekhar S, Gebreselassie T. DHS Working Papers: factors affecting maternal health care seeking behavior in Rwanda. No. 59. Calverton: US Aid; 2008. 
48. Babalola S, Fatusi A. Determinants of use of maternal health services in Nigeria: looking beyond individual and household factors. BMC Pregnancy Childbirth. 2009;9(1):43.

49. Kitui J, Lewis S, Davey G. Factors influencing place of delivery for women in Kenya: an analysis of the Kenya demographic and health survey, 2008/2009. BMC Pregnancy Childbirth. 2013;13(1):40.

50. Ochako R, Fotso J-C, Ikamari L, Khasakhala A. Utilization of maternal health services among young women in Kenya: insights from the Kenya Demographic and Health Survey, 2003. BMC Pregnancy Childbirth. 2011;11(1):1.

51. WHO. WHO guideline on preventing early pregnancy and poor reproductive health outcomes among adolescents in developing countries. Geneva: WHO Press; 2011.

52. Mason E, McDougall L, Lawn JE, Gupta A, Claeson M, Pillay Y, Presern C, Lukong MB, Mann G, Wijnroks M. From evidence to action to deliver a healthy start for the next generation. Lancet. 2014;384(9941):455-67.

53. Requejo JH, Bryce J, Barros AJ, Berman P, Bhutta Z, Chopra M, Daelmans B, de Francisco A, Lawn J, Maliqi B. Countdown to 2015 and beyond: fulfilling the health agenda for women and children. Lancet. 2015;385(9966):466-76.

54. Hindin M. The influence of women's early childbearing on subsequent empowerment in sub-Saharan Africa: a cross-national meta analysis. International Center for Research on Women Fertility \& Empowerment Working Paper Series. 2012. p. 003-2012.

55. Pulerwitz J, Gortmaker SL, DeJong W. Measuring sexual relationship power in HIV/STD research. Sex Roles. 2000;42(7-8):637-60.

56. Pulerwitz J, Barker G. Measuring attitudes toward gender norms among young men in Brazil: development and psychometric evaluation of the GEM scale. Men Masculinities. 2008;10(3):322-38.

57. Kishor S, Subaiya L. Understanding women's empowerment: a comparative analysis of Demographic and Health Surveys (DHS) data. DHS Comparative Reports No. 20. Calverton: Macro International; 2008.

58. Bearinger LH, Sieving RE, Ferguson J, Sharma V. Global perspectives on the sexual and reproductive health of adolescents: patterns, prevention, and potential. Lancet. 2007;369(9568):1220-31.

59. Magadi MA, Agwanda AO, Obare FO. A comparative analysis of the use of maternal health services between teenagers and older mothers in subSaharan Africa: evidence from Demographic and Health Surveys (DHS). Soc Sci Med. 2007;64(6):1311-25

60. Neal S, Matthews Z, Frost M, Fogstad H, Camacho AV, Laski L. Childbearing in adolescents aged 12-15 years in low resource countries: a neglected issue. New estimates from demographic and household surveys in 42 countries. Acta Obstet Gynecol Scand. 2012;91(9):1114-8.

61. Wellings K, Collumbien M, Slaymaker E, Singh S, Hodges Z, Patel D, Bajos N. Sexual behaviour in context: a global perspective. Lancet. 2006; 368(9548):1706-28.

\section{Submit your next manuscript to BioMed Central and we will help you at every step:}

- We accept pre-submission inquiries

- Our selector tool helps you to find the most relevant journal

- We provide round the clock customer support

- Convenient online submission

- Thorough peer review

- Inclusion in PubMed and all major indexing services

- Maximum visibility for your research

Submit your manuscript at www.biomedcentral.com/submit 